\title{
The Entire E-commerce Application in Guangxi Fruit Industry
}

\author{
Jinhai Lu \\ Guangxi Polytechnic (GXP)
}

\begin{abstract}
Keywords: Entire E-commerce; Fruit Industry; Model Improvement; SPSS Analysis.
\end{abstract}
\begin{abstract}
The development of electronic commerce in Chinese city is well conducted, while agriculture has become more difficult for e-commerce. Small-scale of decentralized management and the majority of market demand contradiction is typical of Chinese agriculture, it means the agricultural development model could not adhere to the traditional e-commerce business. This paper focus on e-business models discussion in agricultural products, as well as the traditional model improvements. The paper started with the analysis of the current status of the domestic agricultural e-commerce, compared to foreign agricultural management model of e-commerce and logistics, proposed one improved agricultural e-commerce development model. And modeling performed by SPSS logistic regression analysis. All this paper work is in order to be able to inject new vitality into the development of e-commerce in agriculture, so as a new socialist countryside construction.
\end{abstract}

\section{Introduction}

Development of the Internet brought great challenges on traditional industries, but also provided favorable conditions for the development of e-commerce. According to CNNIC 33rd report, by the end of 2013, Chinese netizens' scale has reached 618 million, of which the proportion of Internet users in rural population of $28.6 \%$, the scale of 177 million. A huge market demand and opportunity is behind the rapid growth. China as an agricultural country, agricultural products market has a wide range of user needs. However, as a traditional industry, the agriculture need product cycle is long, difficult to distribution, vulnerable to natural climate, to some extent, restrict the development of agricultural trade. The author analyzed several existing agricultural e-commerce model in management operations, logistics and other aspects, trying to figure out better ideas for the agricultural development of electronic commerce, providing management of the Internet era of modern agriculture, operations and profitability adaptation mode.

\section{Status of China's Fruit E-commerce}

Information infrastructure is a prerequisite for agricultural e-commerce development. Since 1995, China has published a series of policies to strengthen the modernization of agriculture in rural areas of information, to protect the development of e-commerce in agriculture.

Any industry and e-commerce is inseparable to choose to build their own management pattern, agricultural e-commerce is the same. The formation of the current agricultural e-commerce three levels: the first layer is to provide agricultural information service network; The second level is the web site provides not only the supply and demand information, but also provides an online auction, online trading and other forms of trade commission; The third level is the highest level, in addition to online e-commerce, information on online trading of agricultural products, can also realize transactions online payment [1].

China's central government, the ministry of agriculture, ministry of commerce, ministry of science and technology departments such as agricultural product circulation is becoming more and more emphasis on information technology, it is an important information security circulation of agricultural products. By the end of 2012, China's ministry of commerce issued guidance to accelerate the flow of fresh agricultural innovation plans to encourage the use of the Internet, network and other modern information technology, and combined with online and offline fresh produce online wholesale and retail network; In 2013, wang Yang, deputy prime minister of agriculture and the 
ministry of commerce of the ministry of foreign affairs asked seize the commanding heights agricultural electricity supplier, in January 2014, the party central committee and the state council issued "on deepening the rural reform, to speed up the rural modernization guidance," the proposal to start the flow of liquidity rural agricultural engineering facilities and upgrade the wholesale information, strengthen the construction of agricultural e-commerce platform. Meanwhile, Chinese farmer cooperatives are developing in a fast speed, agricultural enterprises are playing an increasingly important role in the processing of agricultural products, marketing, contract farming, the main force circulation of agricultural enterprises is gradually taking shape, becoming the organization to ensure that farmers get rich.

\section{Status of Fruit E-commerce Platform}

Respect the market share[2] of agricultural e-commerce, the current platform can be divided into three categories, one category is led by Alibaba platform and its agricultural trading platform, one is Jingdong, Shop No. 1and other e-commerce platform which was operated well in 3C and then expand into agricultural products, and last ones are the professional agricultural e-commerce sites.

According to the 2013 agricultural research center released a white paper, ali, the current registered address in about 720000 sellers of villages and towns, including taobao (including mall) nearly 480000 sellers, Sumaitong nearly 240000 alibaba account.

In Alibaba platform, "Network (platform) + Company (network operators) + Farmers" is the most common business model. This model with low cost, low risk, high degree of freedom, is especially suitable for new rural people selling agricultural products online. In 2010, Alibaba cooperated with Xinjiang Alar to build the first e-commerce platform with characteristics [3]. With Alibaba platform, sales of agricultural products maintain a stable rapid growth. 1688. com is a small business e-commerce platform for domestic trade of Ali, focus on domestic network wholesale business. In 2013, it create two projects in the field of agricultural[4], one is Food Specialty Mall and the other is Brand City,to help companies with potential or with the production capacity (or product) to build brand and expand distribution channels for enterprises to achieve wholesale.

Jingdong mall is China's leading e-commerce company, sales of 3 c products. Jingdong online new channel was opened in early 2012, now has covered the aquaculture seafood, fruits, vegetables, eggs, meat, and other eight major categories, from the first half of 2012 sales nearly five times more than in 2011 increased by 20\% month-on-month. Shop No. 1 is the first online supermarket in China, several sets of e-commerce management system with the international advanced level are independent researched and has a number of patents and software copyrights. Shop No.1 officially launched its fresh channel in Beijing in 2013[6]. Fresh comprehensive business logistic is totally used its strategic partner-Wal-Mart's supply chain. This provides a strong guarantee for the quality of fresh products of Shop No. 1, and also for agricultural products and distribution.

The third category is the Professional agricultural e-commerce websites: This type of site was created in the trend of electronic trading of agricultural products, in order to produce tailored professional e-commerce platform. Usually they covers most of the agricultural products of the category and have a more detailed classification. Most agricultural products (like trees, seeds) are products farmer needs. It mainly provides information on supply and demand, most of online transactions are supported.

\section{Foreign agricultural e-commerce situation}

\subsection{United States}

As one of the countries with the highest degree of information technology, the United States launched the earliest agricultural e-commerce, which the Internet plays an important role in this process. The U.S. has more than 400 large-scale agricultural sites[7]. In addition, the United States also have large agricultural enterprises in developing their agricultural e-commerce. For crop farms, 71 percent have computer access and 45 percent use a computer for their farm business in 2013, both 
up 4 percentage points from 2011. Internet access for crop farms has increased to 68 percent in 2013, compared with 64 percent in 2011. In 2013, a total of 70 percent of livestock farms have computer access and 66 percent have Internet access[8].
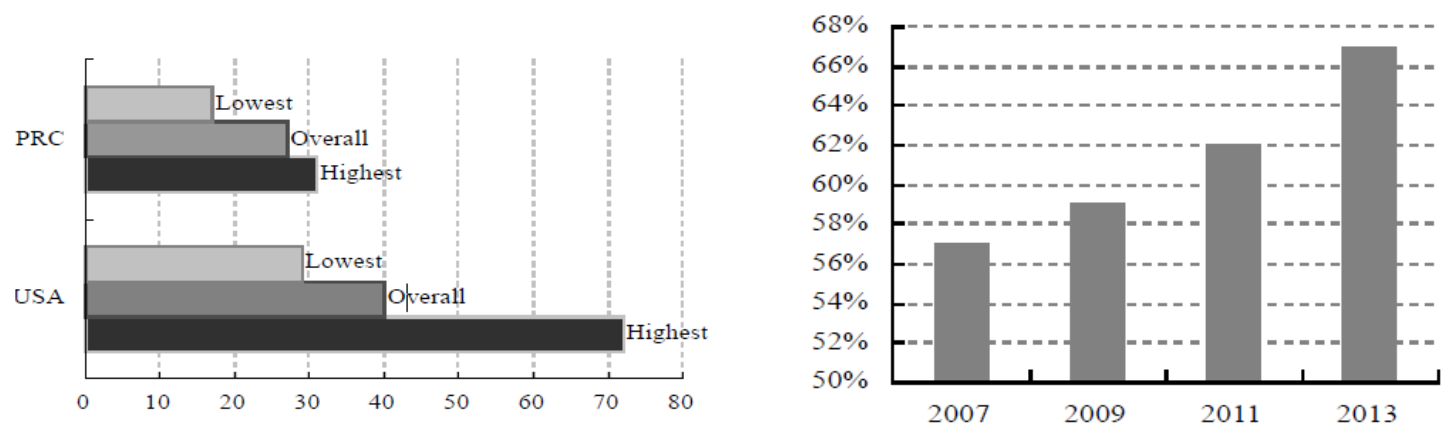

\subsection{Japan}

Japanese agricultural market information service system mainly consists of two components, one is market information service system. To 2005, Japan has achieved 82 domestic agricultural products wholesale markets and 564 district central wholesale market sales volume and real-time networking publishing a daily import and export customs clearance amounts of various agricultural products, agricultural producers and sellers can be easily obtained from the Internet found daily, monthly, accurate to kilograms of various agricultural products sales for the year. Another is the the market forecast system production quantities and prices of various agricultural products. With accurate market information provided by the two systems, each farmer is on the domestic market and the world market, prices, production quantities and other well known and can be determined and adjusted production and yield varieties according to their actual ability to make production in a specific situation, highly ordered statement[9].

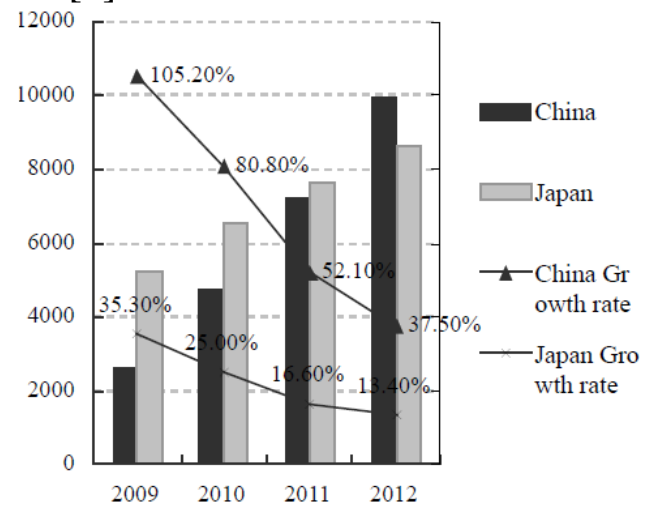

For some of the relatively undeveloped areas in Japan, where network infrastructure is not perfect, farmers' e-commerce awareness is weak, Japan has also taken effective measures, including building of the hardware facilities of electronic commerce, training and education seminars for all farmers, to establish a sound transportation and distribution of product system[10]. Therefore, e-commerce in Japan has been developed overall.

\section{The Current Problems}

\subsection{Information Infrastructure}

By the end of December 2013, China's Internet users accounted for $28.6 \%$ of the rural population, increased 2,101 million compared with 2012. Although rural and urban users netizens gradually narrowing the gap, the total number of Internet users from a population perspective, the Internet in rural has not yet reached the universal scale [11]. Rural e-commerce development gap is quite big, and there is a considerable positive relationship between the levels of economic development. Shanghai, Beijing, shandong brings the general development level of country, based on information technology investment in agriculture and rural development of e-commerce is far higher than the national average, and the level of economic development of qinghai, Tibet and other parts of the 
backward rural information infrastructure investment is also very poor [12]. Overall, most of the provinces are in the general level of e-commerce development and western regions are significantly behind the national average.

\subsection{Agricultural Product Specification Standards}

In China while standardized has been reached, there are two problems: First, the lack of standardization of the number of agricultural products, as China's agricultural market is not mature, the lack of norms and standards of the course in agricultural trade, and in e-commerce extensive use of standard contracts and text and transaction processes are clearly defined, limiting the dealing of e-commerce transactions. In 2004 China started agricultural grading standards [13], the most important including: the national standard of 11 vegetable quality classification, industry 102 standards; 10 national standards for fresh fruit quality grading, involving 10 kinds of fruit industry, the 63 industry standards, involving 63 kinds of fruit; Grains and its processed products 176 quality standards(21 abolished), where 66 national standards, 110 industry standards, including 18 standards of aspects of national fuel. Agricultural production is seasonal, easy to change, and so perishable, so logistics need a certain size and has a high-quality refrigerated transportation equipment, substantial investment is needed. In order to keep the product will not rot, just need to build houses, but also must be chilled + frozen mixed delivery vehicles, refrigerated and heated equipment crates, and Home Delivery Services refrigerated distribution tool. Meanwhile, agricultural products have the characteristics of wide variety, generally small-scale production units, and multiple point's distribution. Logistics is technical difficulty. According to the survey. China's logistics costs are generally $30 \%$ to $40 \%$ of the total cost. In developed countries is generally about $10 \%$ [14]. Affected by traditional ways of producing and marketing, some areas, where farmers all by themselves buy their necessary materials and organize their producing and marketing, have a low logistics degree in this process. So, basically, supply chain of agricultural products is divided into 2 segments-one is the tache of "producing-circulating", that is, the tache between farmers and wholesale market or; the other is the tache of "circulating-consuming", that is, the tache between consumers and wholesale market or. In addition, seasonal market and intermittent purchase cause indentations in the whole tache of supply chain. At the same time, the insufficient abilities of storage and transportation, together with the behindhand facilities for them, greatly influence the circulation and connection of supply chain [15].

\section{Our Proposed Model}

According to the problems during the e-business process of agricultural, this paper proposes a 'middleman' model. Four parts are included in the model: Rural cooperatives, individual farmers, Local service providers and the third-party e-commerce platforms.

Local service providers have many local information resources, responsible for coordinating the local government, individual farmers, rural cooperatives and third-party e-commerce platform. Service providers will bring products of individual farmers and rural agricultural cooperatives together, and the third-party e-commerce platform sells them in a range of nationwide.

Thus, even if farmers are unawareness of how to use the network, or the information does not meet construction standards, farmers can still produce sales through e-commerce channels. Third-party e-commerce platforms send feedback to service providers, service providers arrive at a decision to adapt to the season's best planting program through data analysis, strategic decision-making and other modern methods, and then tell local farmers what to plant in this time. Meanwhile, sales of agricultural products in a period time will be reflected to the local government, in order to publish corresponding policies that would be beneficial to the local sales of agricultural products according to the situation reflected.

In this model, the service provider plays a transmission of information and the role of the connection parties. In traditional agricultural e-commerce model, there is information asymmetry problem among e-commerce platform, governments and farmers. Platforms acquire agricultural products without aiming, wasting time and energy, resulted in costs increment; farmers only know 
about farming but have no ability to investigate sales of agricultural products; Government cannot be fully accurate understanding of local conditions, and therefore cannot put the appropriate policies in accordance with the truth. Service providers work through the coordination of tripartite information with the use of modern means of information and decision-making, to make agricultural e-commerce information technology to achieve the maximum efficiency.

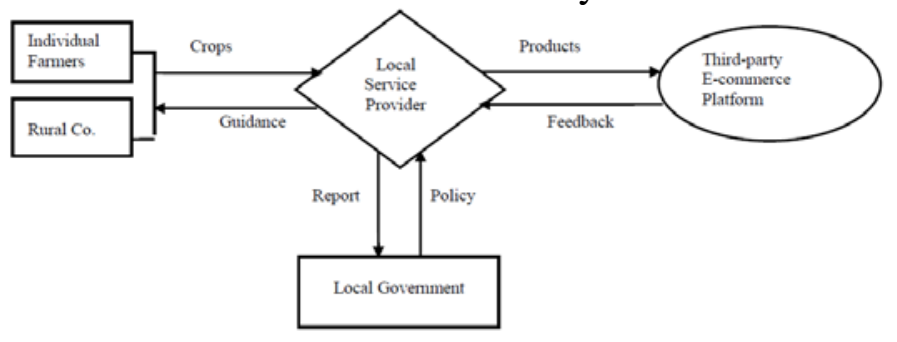

\section{The Model Assessment}

\subsection{Establishment of agricultural econometric model}

Electronic commerce risk mainly refers to the risk of e-commerce activities, e-commerce has brought the uncertainty and the risk of loss. As a result, we can minimize the risk of agricultural e-commerce defined as: the possibility of damage, confidential data in the process of the electronic commerce economic activity and agriculture or loss on the possibility of running business activities of the financial mechanism and fund [16]. Inspired by Yi's risk assessment model[17], according to earlier assumptions made, agriculture e-commerce applications may be affected by the following main factors: the potential benefits of enterprise (R); Industry competitive pressure (P); Convenience of information acquisition(C); Service convenience (S); Trading security (G); inter-regional factors are difficult to quantify, using dummy variables D represents. Model can be expressed as a function of the following form:

$$
E_{i}=F(P C S R D)+e
$$

In the formula, Ei means the i numbers of companies using e-commerce in agricultural, e is a random error term. Since in Yi's paper about the potential benefits(R) did not give a clear explanation, and this article is not involved in the discussion about the technical aspects of the network during electronic transactions,thus security $(\mathrm{G})$ and potential benefits(R) are not considered. For the service-driven model, we have the competitive pressure in the industry $(\mathrm{P})$; Convenience of information acquisition(C); Service convenience (S) to evaluate the model has the ability to promote the development of electronic commerce. With specific cases to assess regional factors (D).

\subsection{Verification}

Before Suichang mode is realized, Suichang agricultural production, is mostly retailing, farmers selling agricultural products through traditional channels.

Since 2010, Suichang entered a phase of rapid development of e-commerce. Birth of Suichang Online Shop Association has played a key role of cluster development of e-commerce in Suichang. The Association established agricultural distribution platform, put together with retail farmers and rural cooperatives. The pressure of integration of resources making more and more original cooperatives and farmers which did not understand e-business in the past joined into local service platform. Moreover, the service platform provides an interface for local farmers and agricultural resources professional information, enables local suppliers to obtain information more easily.

Along with the development of local service providers, the data of e-commerce also grow in leaps and bounds. In the month of Suiwang company founded, the number of online sellers in Suichang increased by $80 \%$. The development of e-commerce led to the improvement of the county's economic growth and people's living standards. GDP is increased from 2.6 billion yuan in 2004 to 7.67 billion yuan in 2013. Online consumption of per people is nearly a thousand yuan on average[20]. 


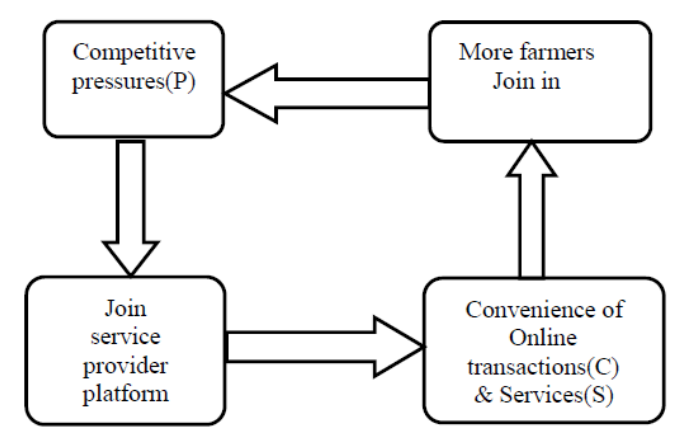

\section{Conclusion and Summary}

E-commerce is the trend of the development of agricultural produce, and also the means to achieve modernization. Mature of agricultural e-commerce model requires not only changes in technology, but also need to adjust the operating model and infrastructure construction. The traditional methods can not achieve e-commerce across the country, and therefore need to adjust business models based on local circumstances. If we establish a local e-commerce service provider, connect the various parts of e-commerce process to a effective integration of resources together, it will accelerate the pace of e-commerce development in rural areas.The model focuses on the information flow among governments, third-party platform and farmers, aiming to maximize the business efficiency. China is a large agricultural country with the vast market demand for agricultural products. China's agricultural e-commerce development should explore its own way in accordance with the actual situation instead of following others.

\section{References}

[1]Tianshi H, Tiexin F. Chinese e-commerce development agricultural food analysis [J]. Issues in Agricultural Economy, 2005, 1000-6389(5): 23-27. (in Chinese)

[2]Cequn L, Ying L. Status and the use of third-party e-commerce application platform strategy [J]. Library and Information Service, 2010, 54(14): 131-135. (in Chinese)

[3]Min J. Agricultural Alibaba e-commerce model [J]. Agricultural Economics, 2013(5): 33-35. (in Chinese)

[4]Ruidong Z, Liang C. Ali agricultural e-commerce white paper [EB/OL].[2013-3-1]. http://i.aliresearch.com/img/20140312/20140312151517.pdf.

[5]Xie Z, Zhao S. Analysis on a successful development model of domestic B2C in China-decode “Jingdong Password” [M]. ICEE, in Press, 2010(2217-2221).

[6]Lindong G. The 1st shop-Dark horse of Chinese e-commerce [J]. Shanghai Commercial, 2011(10): 15-17. (in Chinese)

[7]Kim J, Kahhat R, Al A B E. Energy and environmental flow model for a sustainable networked book delivery system in the United States [C]// Electronics and the Environment, 2008. ISEE, IEEE International Symposium on: IEEE, 2008: 1-2.

[8]UCDA. Farm computer usage and ownership [EB/OL]. [2013-9-1]. http://www. nass.usda.gov /Publications/Methodology_and_Data_Quality/Computer_Usage/08_2013/fmpc0813.pdf

[9]Takamori H, Waseda U Tokyo, Nagasaka. Toward designing value supportive infrastructure for electricity trading [C]// E-Commerce Technology and the 4th IEEE International Conference on Enterprise Computing, E-Commerce, and E-Services, 2007. CEC/EEE 2007. The 9th IEEE International Conference on: IEEE, 2007: 167-174. 